\title{
WATERSHED RUNOFF AND RIVER FLOOD MODELING IN LAND USE PLANNING
}

\author{
Marcello Niedda, Mauro Greppi
}

\section{Introduction}

The study of the flooding processes is an important tool in planning land use in the areas along river paths. The definition of a flood risk for an area of land is of strategic importance when planning its use. In Italy there are regional laws prescribing that there must be knowledge of the potential flood risk of an area of land before planning its use. Nevertheless, the poor experimental knowledge of the flooded areas due to the rarity of flooding makes it difficult to define the flood risk level for an area of land without using an hydrological model.

The Shallow Water Equations (SWE) methodology is an important step ahead when compared with the 1D approach widely used until now (e.g.: HEC-RAS). In low slope landscapes the 1D approximation is not satisfactory for studying a complex morphology. Now it is better to use a 2D approach for studying flooding events [Bates 2000, Horritt, 2000, Horritt 2001a,b, Aronica 2002, Defina 2000], but usually the numerical methodology uses SWE in a simplified form (hyperbolic, diffusive or kinematic model), while there are still few applications based on the complete equations. New methodologies in numerical schemes to solve the (2D) flow equations now offer, if carefully validated, the possibility of using these solutions to define flood risk for land along river paths. The simplified models do not allow one to study local inertia terms. They can satisfactorily describe the flooded surface but not the wave front dynamic.

In this paper a numerical Lagrangian (ADI) model of the SWE in a complete form is used, coupled with a simple wetting-drying algorithm. The model was proposed by Greppi [1993] and recently validated [Niedda 2007]. Mathematical models based on the

Paper received 25.10.2009; accepted 10.03.2010

Prof. Marcello NiedDA, Dipartimento di Ingegneria del Territorio, Università di Sassari, Viale Italia, 39, 07100 Sassari, Italy, niedda@uniss.it.

Prof. MAURO GREPPI, Dipartimento di Ingegneria Agraria, Università di Milano, Via Celoria, 2, 20133 Milano, Italy, mauro.greppi@unimi.it. shallow-water approximation have quite a long tradition of obtaining solutions whose precision is compatible with those needed in engineering [Galland 1991, Cheng 1993, Yu 1998, Unnikrishnan 1999].

The flow hydrograph of the upstream watershed is the inflow boundary condition of the flooded area and it is calculated using a hydrological model at the basin scale. To do this a finite difference distributed model for the continuous simulation of the coupled subsurface-channel flow [Niedda 2000, 2004], is applied to the upper basin. This modeling aims to minimize the number of parameters and processes represented, while the flow routing components are physically based. Subsurface flow is simplified to a 2D horizontal representation. Surface flow is simplified to a kinematic 1D representation along the channel network. Since on shallow and sloping soils with high infiltration capacity the saturation-excess mechanism of runoff production prevails [Dunne 1970], the infiltration-excess mechanism is ignored. Watershed topography is discretized using the grid-DEM, which also defines the computational grid of the finite difference numerical schemes.

This research aims to improve our comprehension of river flood inundation in flat areas through the integration of a watershed runoff forecast model with a robust numerical scheme of the $2 \mathrm{D}$ complete form for shallow water equations.

\section{Materials and methods}

\subsection{The finite difference hydrological model}

Surface interception and soil moisture store, evapotranspiration, 1D open channel flow and 2D horizontal subsurface flow are modeled at the basin scale. Vertical and lateral flows between soil, surface and atmosphere domains are shown in the conceptual representation in Figure 1, where $P$ is precipitation, $E$ is evaporation from interception storage of capacity $S$, and $E T$ is actual evapotranspiration. There is no infiltration equation and all excess precipitation $P_{e}$ from interception storage enters the soil. Soil moisture $\theta$ 


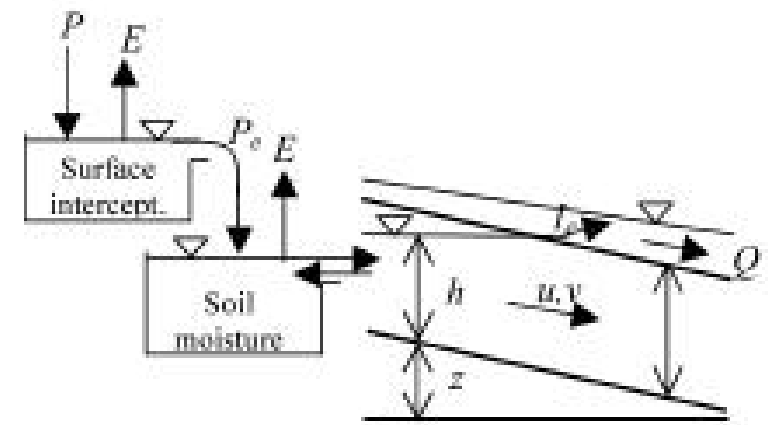

Fig. 1 - Conceptual representation for each space-grid cell of the vertical and lateral flows between soil, surface and atmosphere domains.

varies between soil porosity $\phi$ and residual content, for simplicity taken as equal to zero. It is assumed that soil thickness $H$ first wets up to the moisture content $\theta_{33}$ held at $-33 \mathrm{kPa}$ matric potential. Only when the soil moisture exceeds $\theta_{33}$ do excess volumes constitute an input for the subsurface flow governed by Darcy's law. The zero-flow boundary condition is adopted at the catchment divide and at the base of the active permeable layer. When the height of the water table $h$ intercepts the ground surface $(h>H)$, saturation-excess $I_{e}$ is an input in surface flow. Surface runoff propagates downstream along the channel network and, if it reaches areas that are not yet saturated $(h<H)$, downslope reinfiltration is allowed.

The differential equations describing unsteady and spatially varied groundwater and open channel flow can be expressed as:

$$
\begin{gathered}
\eta_{e} \frac{\partial h}{\partial t}+\frac{\partial(h u)}{\partial x}+\frac{\partial(h v)}{\partial y}-P_{e}-E T-I_{c}, \theta>\theta_{33} \\
I_{e}=0 \quad \text { if } 0 \leq h \leq H, \\
I_{e}=\frac{n_{c}(h-H)}{d t} \text { if } h>H ; \\
u=-K \frac{\partial(z+h)}{\partial x}, \\
v=-K \frac{\partial(z+h)}{\partial y} ; \\
K-\frac{h}{H} K_{s} ; \\
\frac{\partial Q}{\partial s}+\frac{\partial A}{\partial t}=\frac{I_{e} \cdot d x-d y}{d s}, Q \geq 0, \mathrm{~A}=0 ; \\
Q=n^{-1} F^{23} l^{1 / 2} A^{w 1} ;
\end{gathered}
$$

where $t$ is time; $x$ and $y$, orthogonal coordinate axes in the horizontal plane; $u$ and $v$, Darcy velocities in $x$ and $y$-directions; $z$, elevation of the impermeable layer; $K$, soil hydraulic conductivity; $n_{e}=\phi-\theta_{33}$, drainable porosity; $s$, longitudinal coordinate of the open channel network; $Q$, surface flow discharge; $A$, surface flow cross-sectional area; $i$ channel bed slope; $n$, Manning's roughness; $F$, shape factor in the expression for the hydraulic radius equal to $F \times A^{1 / 2}$. In accordance with Dupuit's approximation, (1a), (2a) and (2b) are the mass and momentum conservation equations for 2D saturated subsurface flow. The equation (2c) is used to model vertical heterogeneity of soil with hydraulic conductivity decreasing with depth, where $K_{S}$ is the saturated hydraulic conductivity at the surface. In accordance with the Saint-Venant equations and the kinematic approximation, (3) and (4) are the mass and momentum conservation equations for $1 \mathrm{D}$ gradually varied surface flow.

The partial differential equations (1-4) for surface and subsurface flow are solved by conventional finite difference schemes. The same numerical discretization is considered for the soil and channel flow components, with time step $\Delta t$ and uniform spatial steps $\Delta s=\Delta x=\Delta y$. Space cell of grid-DEM and the other landscape parameters have also been set as equal to this size. For the 2D subsurface flow, by combining equations (1) and (2) and substituting the variable $h$ with the new dependent variable $\zeta=n_{e} h$, the solution equation, written in finite difference form for the internal element $(i, j)$ of the computational space-grid and the time level $n+1$, is

$$
\begin{aligned}
& \zeta_{i, j}^{n+1}=\zeta_{i, j}^{n}+\frac{\Delta t}{4 \Delta s^{2}}\left(f_{i+1 / 2, j}-f_{i-1 / 2, j}+f_{i, j+1 / 2}-f_{i, j-1 / 2}\right)^{r} \\
& +\Delta i\left(P_{e}-E T-I_{e} x_{j, j}^{i+1} .\right. \\
& \quad \text { with }
\end{aligned}
$$$$
\begin{aligned}
f_{k+1 / 2}^{n}=\frac{\left(K_{s k+1}+K_{s k}\right)}{\left(H_{k+1}+H_{k}\right)}\left(\frac{\xi_{i+1}^{n}}{n_{e+1}}+\frac{\xi_{k}^{n}}{n_{k}}\right)^{2} & \left(z_{k+1}+\frac{\xi_{k+1}^{n}}{n_{e k+1}}-z_{k}-\frac{\xi_{i}^{n}}{n_{d k}}\right)
\end{aligned}
$$

Equation (5) is obtained using a one-step, explicit, time-forward and space-centred 2D scheme. The simple scheme used is not unconditionally stable, but the small values of soil hydraulic conductivity meet the necessary Courant condition for explicit schemes [Abbott 1992, Weiyan 1992]. This explicit scheme does, however, have the advantage of reducing the amount of computer time and core storage, as these tend to increase greatly with basin size and with decreasing space and time steps. The space and time steps size must, indeed, be small to meet the accuracy requirement of the difference solution.

For the 1D surface flow the mass conservation equation (3), written in finite difference form for the channel network link between the upstream grid node $i$ and the downstream grid node $i+1$, is

$$
\begin{aligned}
& \frac{\lambda\left(Q_{i+1}^{n+1}-Q_{i}^{n+1}\right)(1-\lambda)\left(Q_{i+1}^{n}-Q_{i}^{n}\right)_{+}}{\Delta_{s}} \\
& \frac{\left(A_{i+1}^{n+1}-A_{i+1}^{v}\right)+\left(A_{i}^{n+1}-A_{i}^{n}\right)}{2 \Delta t}=I_{e+1}^{n+1}-\Delta s
\end{aligned}
$$

Equation (6) is obtained using the weighted fourpoint implicit finite difference scheme, where the space-weighting discretization coefficient is set to 0.5 . The value of the time-weighting coefficient $\lambda=0.6$ is 
used to prevent instability conditions in the centred scheme $(\lambda=0.5)$, and to decrease the numerical dissipation of the unconditionally stable fully implicit scheme $(\lambda=1)$. The application of this scheme is based on the spatial structure of the channel network extracted from the grid-DEM by an automatic procedure which makes use of Operational Research algorithms for "network flows" [Niedda 1996]. The connected tree structure of the channel network is stored in vector form with graph techniques. These are are very efficient for large networks as they reduce computer time and optimize memory store. Equations (4) and (6) are combined and solved starting from the upstream nodes, where the boundary condition $Q_{0}=0$ is assigned, and following the connected tree network down to the root node.

\subsection{The finite difference hydrodynamic model}

Since flooded areas can generally be considered as shallow in relation to their wideness and their length, shallow water equations were used to simulate current fields and investigate the wetting surface reached during the flood [Luettich 2002, Weiyan 1992]. The depth-averaged approach is believed to be adequate in flooded areas, if the vertical velocity is limited.

Based on the simplifications described above, the governing equations for the hydrodynamic model are the following depth-averaged shallow-water equations. Letting $t$ be the time coordinate, $x$ and $y$ two horizontal Cartesian coordinates, $U(x, y, t)$ and $V(x, y$, $t)$ the respective depth-averaged flow velocity components, $z(x, y, t)$ the water surface elevation, $d(x, y$, $t)=z(x, y, t)-z_{0}(x, y)$ the water depth, $z_{0}(x, y)$ the bottom elevation with bed change removed, $d / d t$ the substantial derivative, then (7) is the mass continuity equation, and (8) and (9) are the respective $x$ - and $y$-momentum equations:

$$
\begin{gathered}
\frac{\partial d}{\partial t}+\frac{\partial(d U)}{\partial x}+\frac{\partial(d V)}{\partial y}=0 \\
\frac{d U}{d t}=-g \frac{\partial z}{\partial x}+\frac{\tau_{x}-\tau}{\rho h}+v_{2}\left(\frac{\partial^{2} U}{\partial x^{2}}+\frac{\partial^{2} U}{\partial y^{2}}\right) \\
\frac{d V}{d t}=-g \frac{\partial z}{\partial y}+\frac{\tau_{s y}-\tau_{b y}}{\rho h}+v_{i}\left(\frac{\partial^{2} V}{\partial x^{2}}+\frac{\partial^{2} V}{\partial y^{2}}\right)
\end{gathered}
$$

where $v_{\mathrm{t}}$ is the depth-averaged turbulent kinematic viscosity; $\tau_{b x}$ and $\tau_{b y}$ are the bed shear stresses that are determined by $\tau_{b y}=\rho c_{p} U \sqrt{U^{2}+V^{2}}$ and $\tau_{b y}=\rho c, V \sqrt{U^{2}+V^{2}}$; $c_{f}=g n^{2} d^{-1 / 3}$, in which $n$ is the Manning's roughness coefficient; $\tau_{s x}$ and $\tau_{s y}$ are the surface shear stresses that are determined by $\tau_{i n}=\rho_{a} c_{d} y^{2} \cos \alpha$ and $\tau_{e}-\rho_{s} c_{D} W^{2}$ sene; $\rho_{a}$ is the air density; $W$ is the wind speed at $10 \mathrm{~m}$ height; $c_{D}$ is an adimensional coefficient; and $\alpha$ is the angle between the wind direction and the $x$-coordinate. The turbulent kinematic viscosity is calculated with a simple algebraic eddy viscosity model by, in which $U^{+}=\sqrt{c},\left(U^{2}+V^{2}\right)$ is the maximum shear velocity, and $\alpha_{\mathrm{t}}$ is an empirical coefficient less than $1[\mathrm{Wu}$ 2004, Colombini 2005].

The set of partial differential Eqs. (7-9) was solved using a finite difference scheme which couples the Alternate Direction Implicit (ADI) integration method with the Eulerian-Lagrangian Method (ELM) [Casulli 1990, Ambrosi 1991, Greppi 1993]. In this scheme the variables are defined on the nodes of a staggered grid, which consists of $M \times N$ rectangular cells of dimensions $\Delta x \times \Delta y$. Water surface elevation $z$ is defined at the center of the cell, while the velocity components $U$ and $V$ are defined at the edge [Abbott 1992]. A no-slip condition has been used on solid boundaries. The computational field boundaries and the grid are considered to overlap with the DEM projections. DEM gives the geodetic levels and the bed resistance coefficients, calculated using the land use data. The square mesh makes it easy to describe the transition process wetting - drying of a cell, which is a critical point in the 2D hydrodynamic models used in describing flooding [Balzano 1998, Molinaro 1994]. In agreement with Leendertse [1987], who defined $d=z-z_{0}$ as the difference between the water level and the maximum ground level in the four cell corners, the cell is in or out of the computational field depending on $d>\varepsilon$ or $d<\varepsilon$, where $\varepsilon$ is a reference threshold value.

Initial conditions for velocities and water elevations start from the static state. The boundary condition in the incoming section is the flow hydrograph of the upstream watershed, while in the outflow section the boundary condition is the sea level, ruled by the ebb tide and atmospheric pressure.

\section{Application}

This methodology was used to simulate flooding in the alluvial plane crossed by the Padrongiano river in the North-East of Sardinia (Italy) near Olbia-Costa Smeralda airport (fig. 2). The airport runway and a bridge which crosses the river near its mouth are important tests of the model's forecasting capacity. There are two main river branches crossing the plain which merge in the valley $4 \mathrm{~km}$ from the river mouth (see west and east branch in fig. 2). The river flow in the plain near the mouth is governed by the sea level and tides. Geomorphologic parameters of the studied area: elevation, slope, land uses soil texture and thickness were obtained using a GIS ArcInfo/ArcMap from $1: 10,000$ scale maps for the upstream basin and 1:2,000 scale maps for the alluvial plane. The basin of the Padrongiano river is $438 \mathrm{~km}^{2}$ in area, with an altitude ranging from 1,200 $\mathrm{m}$ to sea level, and an average of $275 \mathrm{~m}$ a.s.1.. The catchment area has an average surface slope of $15 \%$ and a north-easterly aspect. Landuse consists of natural pasture and woodland above an elevation of $100 \mathrm{~m}$, and crop-growing areas and very few urbanized areas below $100 \mathrm{~m}$ a.s.l. The dominant soil type is sandy loam of alluvial origin, overlying 
impermeable bedrock consisting mainly of granite, and, to a lesser extent, metamorphic rock. According to a preliminary survey soil thickness mainly ranges from 20 to $100 \mathrm{~cm}$. Alluvial deposits are found in valley bottoms along streams and their thickness ranges from 100 to $300 \mathrm{~cm}$.

The computational field used to simulate the river hydrodynamics in the alluvial plane near the mouth has a grid of square cells of $5 \mathrm{~m}$ size, which cover the area of $4.25 \mathrm{~km} \times 3.6 \mathrm{~km}$ shown in figure 2 . The inside south border is so far from the mouth that the flow is not influenced by ebb tides and the outside north border in the sea is at such a distance from the mouth that the sea level is not influenced by the river flood. The stability condition of the numerical scheme was satisfied using a time step of $1 \mathrm{~s}$.

Wind conditions use the less favourable North-East wind direction, which is also the more frequent one. The imposed wind intensity was $20 \mathrm{~m} / \mathrm{s}$ from NE, that is against the direction of flow at the river mouth. This type of wind is the most dangerous for the urbanized land along the river during flooding. On the north open boundary toward the sea the boundary condition fixes the water level as $z$ equal to the tide, while the south open boundary corresponds to the two river branches, as shown in figure 2 . The boundary condi-

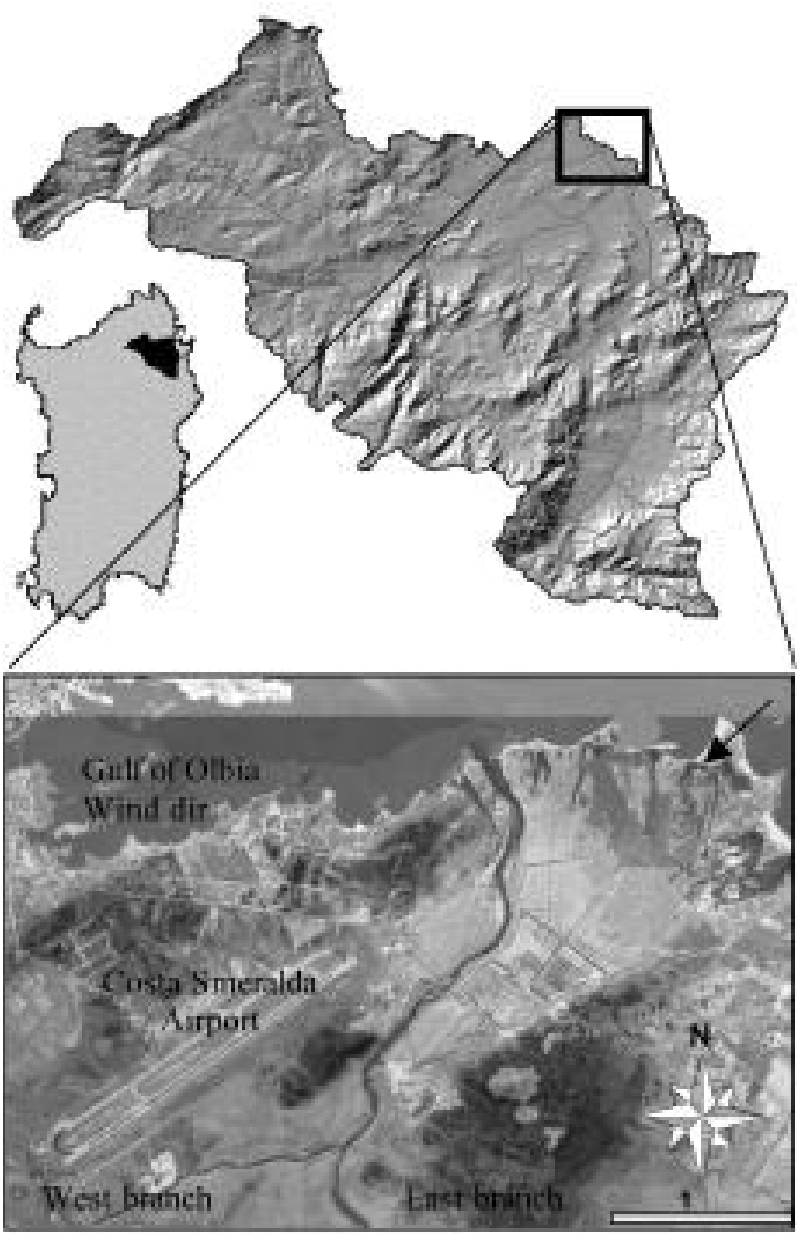

Fig. 2 - Padrongiano basin and alluvial plain of the Padrongiano river in Sardinia (Italy) near Olbia-Costa Smeralda Airport. tion fixes the water velocities, obtained from the watershed flood hydrographs.

\subsection{The basin scale rainfall-runoff simulation}

Flows entering the two river branches, which are the upstream open boundary of the alluvial plane, are computed using the hydrological model applied to the basin of the Padrongiano river. The flood wave simulation at basin scale was run using the rainfall of the synthetic hyetographs obtained for a return period of 500 years. The TCEV probabilistic model best matches the historical rainfall series measured in Sardinia and it is used to calculate the depth duration frequency curves in the Olbia Bay area. The method uses the averaged highest daily rain in one year for this area, which is $\mu=80 \mathrm{~mm}$, to compute the rain depth $P$ (in $\mathrm{mm}$ ) of duration $\tau$ (in hours) with fixed return time $T=500$ years:

$$
\begin{aligned}
& P(\tau)=\frac{\mu(0.437997+1.089 \log T)}{0.886 \cdot 24^{-0.093+0.476 \log M}} \tau^{0.476 \log _{5} \mu-0.004542 \log T-0.4094} \\
& =82 .] \cdot \tau^{0.394}
\end{aligned}
$$

The rainfall was calculated using the depth duration frequency curve (10) in order to estimate the basin peak discharge corresponding to the same return time of the rainfall. The Chicago hyetograph developed by Keifer [1957], shown in figure 3, was used to obtain the most intense and most dangerous rainfall events for each duration that will occur for the fixed return time, $T$. This hyetograph has the peculiar feature that for every duration the mean intensity of the rainfall calculated is equivalent to that calculated using the depth duration frequency curve and it has the advantage that it is less sensitive to duration change. The central part of the Chicago hyetograph is, indeed, constant for growing durations.

The values of the soil moisture contents $\theta_{33}=0.3$, the effective porosity $n_{e}=0.2$, the saturated hydraulic conductivity $K_{\mathrm{S}}=100 \mathrm{~mm} / \mathrm{h}$, the Manning's roughness coefficient $n=0.05$ for natural stream and $n=0.2$ for hill slope, and the volume of vegetation interception $S$ $=1 \mathrm{~mm}$ were chosen. These represent average conditions which are sufficiently uniform to meet the objectives of the model. In agreement with the conditions which ensure consistency and stability in numerical schemes, a time step $\Delta t=300 \mathrm{~s}$ and a space step $\Delta s=$ $25 \mathrm{~m}$ were used. Grid-DEMs and the other input gridmaps were sampled for these sizes. The simulation was run from 24 hours, starting from the initial condition of the soil at field capacity. The simulated hydrograph at the outlet of the Padrongiano river basin and the two river branches are shown in figure 3. The cumulative rainfall was $217 \mathrm{~mm}$, the runoff volume at the outlet $79 \mathrm{~mm}$, and the peak discharge $1506 \mathrm{~m}^{3} / \mathrm{s}$.

\subsection{The 2D flood wave simulation}

This runoff model has been used to calculate forecasted flow hydrographs in the river sections on the 


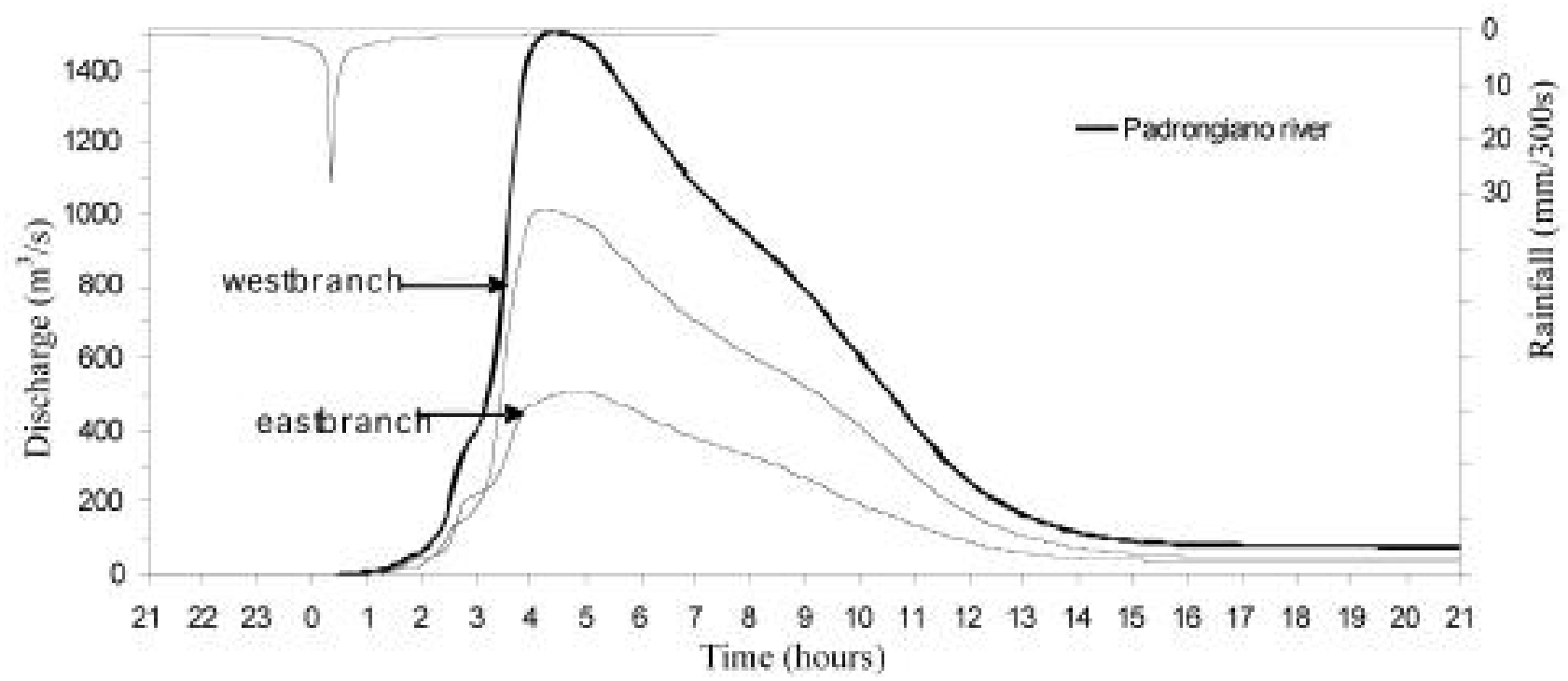

Fig. 3 - Synthetic Chicago hyetograph and corresponding simulated hydrographs for a return period of 500 years in the Padrongiano river and in the two river branches.

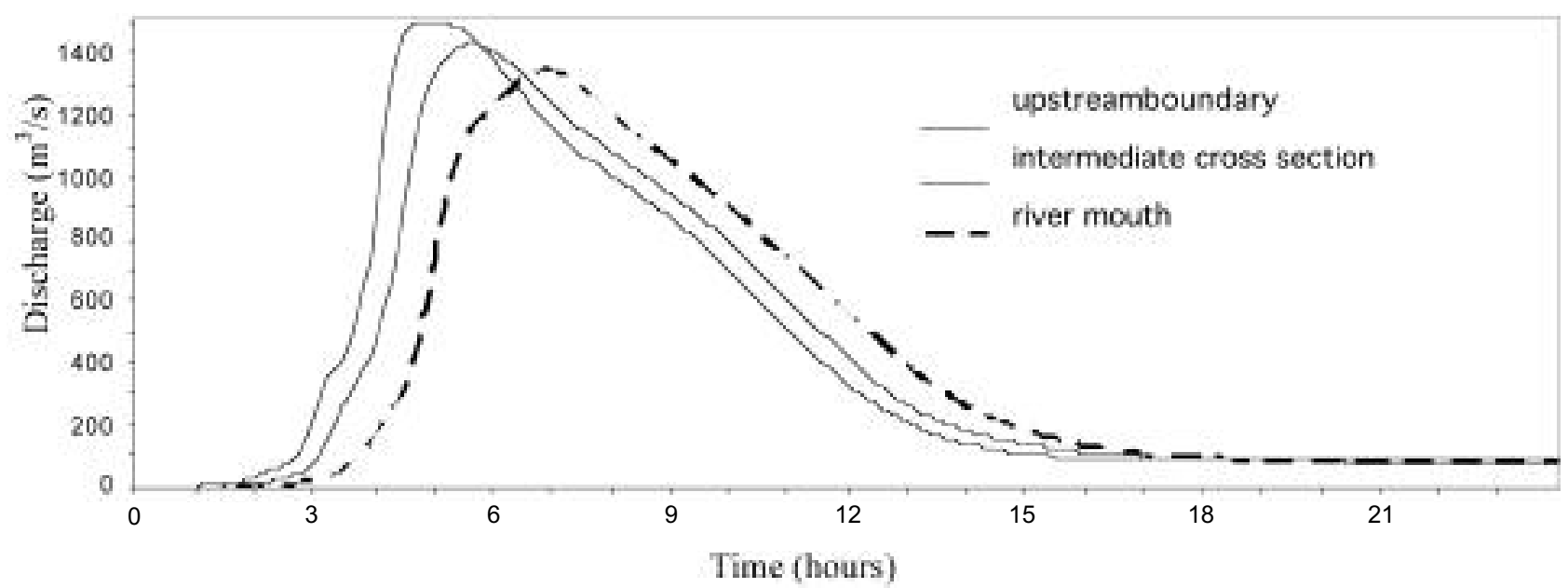

Fig. 4 - Discharge on the upstream boundary, as a sum of the computed hydrographs in the two branches of the Padrongiano river, in an intermediate cross section and at the river mouth.

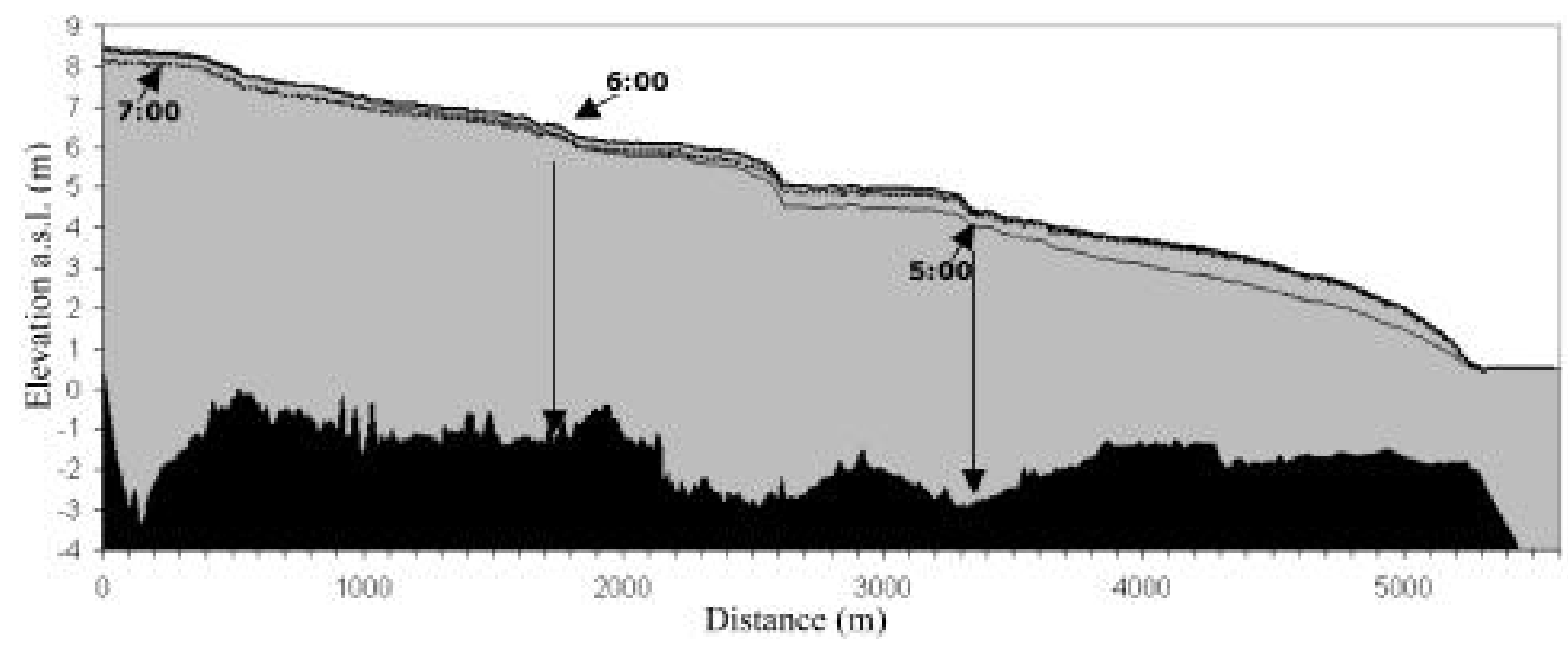

Fig. 5 - River bottom and water free surface profiles after 5,6 and 7 hours from the west branch of the Padrongiano river to the sea. 
inlet boundary of the flooding area considered. The hydrodynamic model based on SWE was then applied. A univariate analysis procedure was used to in-
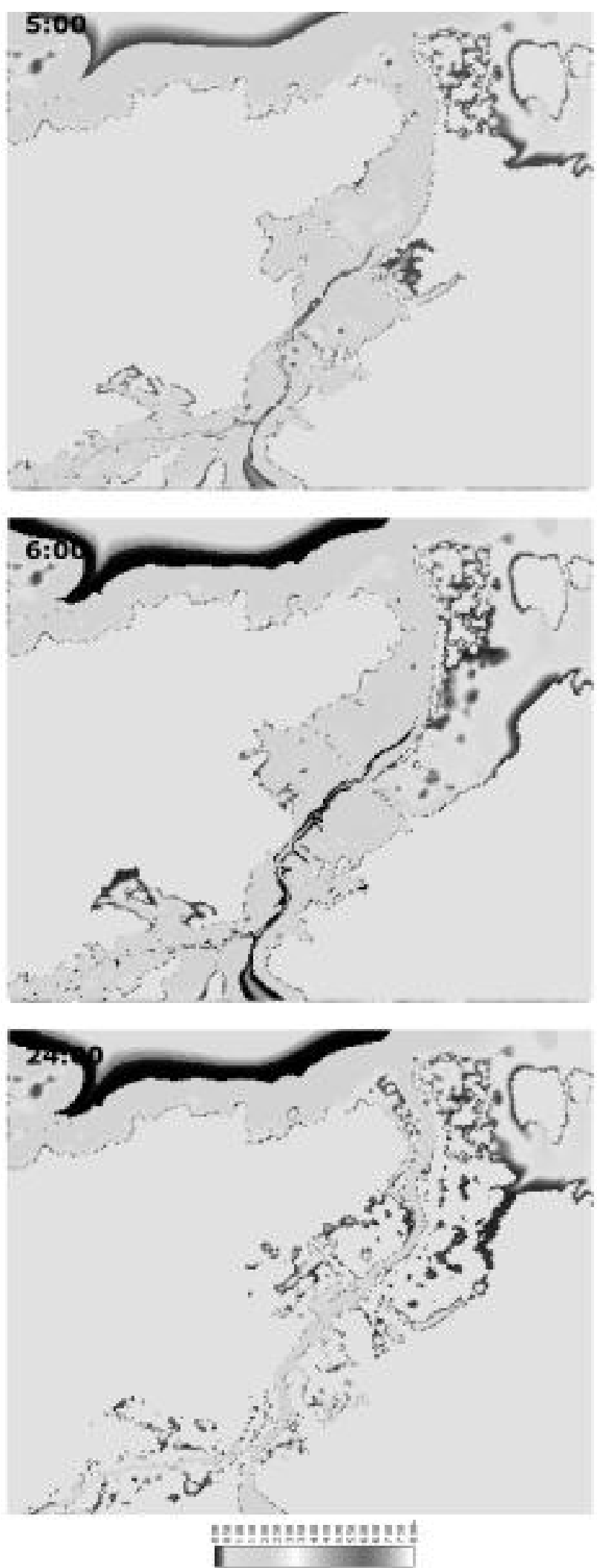

Water depth (m) vestigate the model's sensitivity to the numerical scheme resolutions and parameters, which were set at a constant value throughout the domain. A uniform
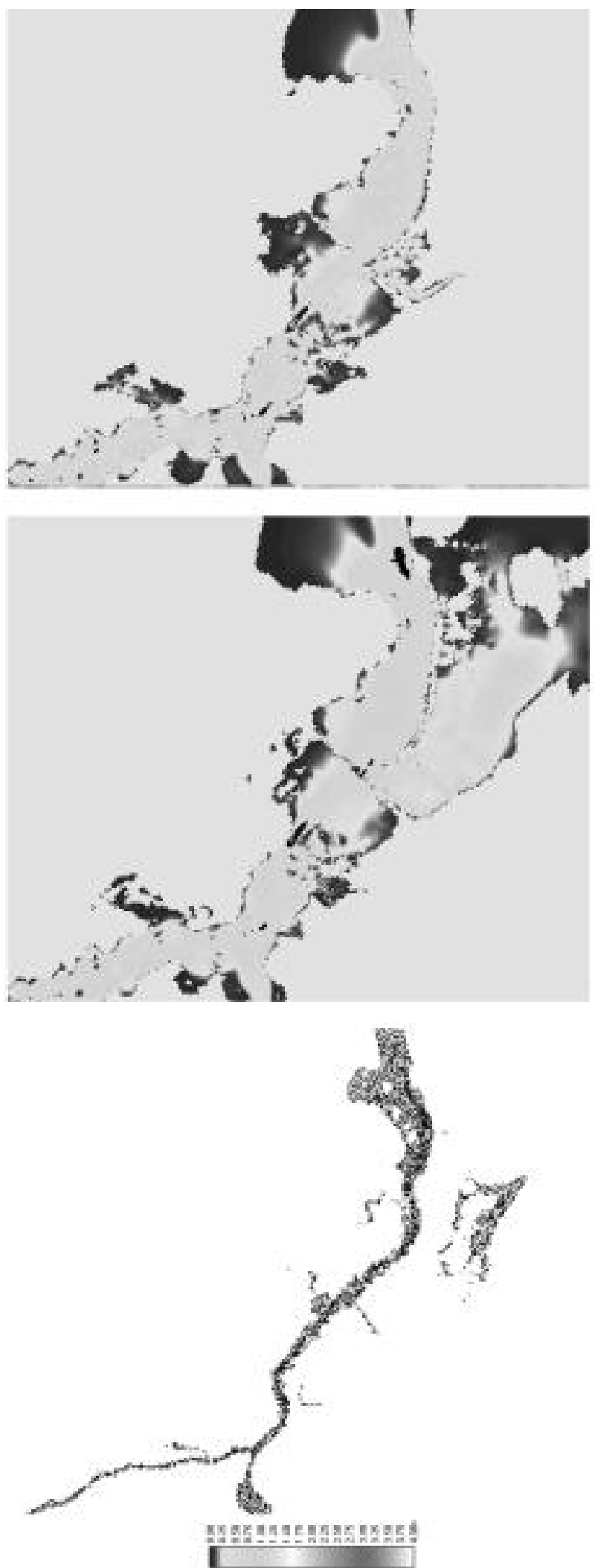

Velocity $(\mathrm{m} / \mathrm{s})$

Fig. 6 - Water depth and velocity at the $5^{\text {th }}, 6^{\text {th }}$ and $24^{\text {th }}$ hours as simulated by the $2 \mathrm{D}$ model in the alluvial plain of the Padrongiano river. 
mesh with spatial increments $\Delta s=2,5$ and 10 m over the computational domain and a time step respectively of $\Delta t=1,2$ and $4 \mathrm{~s}$ were used, which guaranteed stability in all the applications, satisfying the Courant condition. The value of Manning's friction coefficient varies between $n=0.03$ and $0.06 \mathrm{~m}^{-1 / 3} \mathrm{~s}$ [Ding 2004]. The coefficient $\alpha_{\mathrm{t}}$ used to compute the eddy viscosity produced negligible differences, varying between 0 and 1 . Thus, for reasons of simplicity, in the following analysis the horizontal diffusion terms of the momentum equations $(8,9)$ have not been considered. This model was tested and calibrated in a sea lagoon where we monitored the hydrodynamic flow for some years, measuring with care the sea level and the climatic parameters: atmospheric pressure, speed and direction of the wind, air and water temperatures, water salinity etc.. A helical current-meter was also used to monitor the velocity component parallel to the sea channel. Water salinity at different depths was also measured, and a Doppler current-meter was used to measure the depth-averaged velocity at the centre of the river inlet. The observations highlighted the effect on velocity of the friction resistance of the bottom and of the surface. Numerical analyses confirmed that the dynamics of these lagoon areas is mainly controlled by a balance between accelerations, barotropic pressure gradients, and bed and wind stresses, and highlighted that the internal seiche is one of the mechanisms responsible for driving residual currents. The 2D-horizontal model used was accurate in the modeling of tide-generated flow [Niedda 2007].

In the alluvial plane of the Padrongiano river, SWE model results were obtained for a 24 hours running time, during which the flood hydrograph has a rising limb, then a peak, reached after 5-6 hours, and a recession curve. In accordance with the conditions which ensure consistency and stability in numerical schemes, a time step $\Delta t=1 \mathrm{~s}$ and a space step $\Delta s=5 \mathrm{~m}$ were used. Grid-DEMs and the other input grid-maps were sampled for these sizes. During the rising limb and the peak river flow flooded a wide area near the river bed. In figure 4 are respectively plotted: a) the total hydrograph on the upstream boundary, as a sum of the computed hydrographs in the two open branches of the river, b) the hydrograph in an intermediate cross section and c) at the river mouth. The highest discharge values are reached after between 5 and 7 hours and depend on the location of the section along the river path. Flooding changes the river flow peak value. There is a loss of $200 \mathrm{~m}^{3} / \mathrm{s}$ from the total discharge in the incoming sections of $1500 \mathrm{~m}^{3} / \mathrm{s}$, and in the river mouth of 1300 $\mathrm{m}^{3} / \mathrm{s}$. Figure 5 shows the water free surface and the river bottom profile after 5, 6 and 7 hours along the west branch of the river. The steep slope in the water surface in a few sections requires the inertial terms in the equations to describe the wave front propagation. The computed velocities modules and water depths are plotted in figure 6 at the $5^{\text {th }}, 6^{\text {th }}$ and $24^{\text {th }}$ hours sets. At the $5^{\text {th }}$ hour flow floods the land east of the river and starts to overflow the right bank. At the $6^{\text {th }}$ hour the flow floods the land on the right of the river and the road crossing. During flood regression some pools are formed, leaving water in the alluvial plane and then the river flow returns inside the banks (figure 6 at the $24^{\text {th }}$ hours). This simulation of the process seems quite satisfactory and, we trust, it could be used in land use planning to define infrastructure works.

\section{Conclusions}

A robust numerical scheme (ADI-Lagrangian) of the 2D complete form shallow water equations, together with a wetting-drying algorithm based on a topographic DEM and a watershed runoff forecast model, have been applied to simulate flood propagation in an alluvial plain.

In the description of the wetting-drying process a threshold of $1 \mathrm{~cm}$, used as a condition for whether or not to include the cell in the computational field, seems to fit the model well. The numerical model is conservative, ensuring preservation of water volumes with a precision of $10^{-4}$. The steep surface water slope in some sections is evident proof of the importance of SWE inertial terms in wave front propagation. The peak loss of flow during the alluvial plain flooding results in a reduction of about $10 \%$ in the discharge peak at the river mouth. This numerical method, validated in [Greppi 2007] describes flooding in a complex area where the river's morphology was restricted by an airport and road infrastructures.

The 1-D implicit finite difference scheme used for the surface flow simulation in the Padrongiano river basin, which was based on the spatial structure of the channel network extracted from the DEM, made it possible to simulate surface runoff only as channelled flow and to use the roughness coefficient as the sole calibration parameter.

The very long return period of 100-500 years was necessary due to the set of rules regulating land use planning in Italy. As a consequence the runoff model gives very high river discharge peaks and there is not much chance of making experimental observations. On the other hand some description of the river flooding process in these critical conditions is quite important in order to plan land use correctly. In this field one must integrate a basin scale hydrological model and a robust numerical scheme of the $2 \mathrm{D}$ complete SWE form. Being aware of the fact that experimental validation is very difficult [Mignot 2006, Werner 2004], we showed the reliability of the numerical schemes used to get consistent solutions. Nevertheless it is extremely helpful to have a description of likely river flooding in the area considered when planning infrastructures such as the expansion of this airport.

\section{References}

Abbott M.B., 1992. Computational Hydraulics. Ashgate, Vermont, $326 \mathrm{pp}$. 
Ambrosi D., Greppi M., 1991. Numerical solutions for shallow water equations. In: Taylor, C. (Eds.), Numerical Methods in Laminar and Turbulent Flow. Pineridge Press, Stanford, U.K., pp. 1142-1151.

Aronica G., Bates P.D., Horritt M.S., 2002. Assessing the uncertainty in distributed model predictions using observed binary pattern information within GLUE, Hydrological Processes, 16, pp. 2001-2016.

Balzano A., 1998. Evaluation of methods for numerical simulation of wetting and drying in shallow water flow models. Coastal Engineering, 34, 83-107.

Bates P.D., De Roo A.P.J., 2000. A simple raster-based model for flood inundation simulation, Journal of Hydrology, 236, pp. 54-77.

Casulli V., 1990. Semi-implicit finite difference methods for the two-dimensional shallow water equations. Journal of Computational Physics 86, 56-74.

Cheng R.T., Casulli V., Gartner J.W., 1993. Tidal, residual, intertidal mudflat (TRIM) model and its applications to San Francisco Bay, California. Estuarine, Coastal and Shelf Science 36, 235-280.

Colombini M., Stocchino A., 2005. Wind effect in turbulence parametrization. Advances in Water Res. 28, 939-949.

Defina A., 2000. Two-dimensional shallow flow equations for partially dry areas. Water Resour Res, 13(11), 325164.

Ding Y., Jia Y., Wang S.S.Y., 2004. Identification of Manning's roughness coefficients in shallow water flows. Journal of Hydraulic Engineering 130, 501-510.

Dunne T. and Black R.D., 1970. An experimental investigation of runoff production in permeable soils, Water Resour. Res, 6, 478-490.

Galland J.C., Goutal N., Hervouet J.-M., 1991. TELEMAC, a new numerical-model for solving shallow-water equations, Advances in Water Res., 14(3), 138-148.

Greppi M., Niedda M., 1993. Lagoon hydrodynamic and pollution problems, Numerical Methods in Laminar and Turbulent Flow, Pineridge, Swansea UK, 1280-88.

Keifer C.J., Chu H.H., 1957. Synthetic storm pattern for drainage design. Journal of the Hydraulics Division, ASCE.

Horritt M.S., 2000. Calibration and validation of a 2-dimensional finite element flood flow model using satellite radar imagery, Water Resour Res, 36 (11), pp. 3279-91.

Horritt M.S., Bates P.D., 2001a, Effects of spatial resolution on a raster-based model of flood flow, Journal of Hydrology, 253, 239-249.

Horritt M.S., Bates P.D., 2001b. Predicting floodplain inundation: raster-based modelling versus the finite element approach, Hydrological Processes, 15, 825-842.

Leendertse J.J., 1987. Aspects of SIMSYS, A System for Two-Dimensional Flow Computations, RAND Publication R-3572-USGS.

Luettich Jr. R.A., Carr S.D., Reynolds-Fleming J.V., Fulcher C.W., McNinch J.E., 2002. Semi-diurnal seiching in a shallow, microtidal lagoonal estuary. Continental Shelf Research 22, 1669-1681.

Mignot E., Paquier A., Haider S., 2006. Modeling floods in a dense urban area using 2D shallow water equations, Journal of Hydrology, 327, 186-199.

Molinaro P., Natale L., 1994. Modelling flood propagation over initially dry areas, ASCE, New York.

Niedda M., 1996. Use of network algorithms in spatially distributed models for the study of river basin response, in Application of GIS in hydrology and water resources management, edited by K. Kovar, and H.P. Nachtnebel, pp. 207-214, IAHS Publ. 235, Wallingford, U.K.

Niedda M., 2000. Simulation of ground-water flow in steep basin with shallow surface soil, Journal of Hydraulic Engineering, ASCE (USA), v.126/9, 670-678.

Niedda M., 2004. Upscaling hydraulic conductivity by means of entropy of terrain curvature representation, Water Resources Research (USA), Vol. 40, No. 4.

Niedda M., Greppi M., 2007. Tidal, Seiche and Wind Dynamics in a Small Lagoon in the Mediterranean Sea, Estuarine, Coastal and Shelf Science, 74, 21-30.

Unnikrishnan A.S., Gouveia A.D., Vethamony P., 1999. Tidal regime in gulf of Kutch, west coast of India, by 2D model. Journal of Waterway, Port, Coastal, and Ocean Engineering 125, 276-284.

Weiyan T., 1992. Shallow Water Hydrodynamics. Elsevier Oceanography Series, Amsterdam, 434 pp.

Werner M.G.F., 2004. A comparison of flood extent modeling approaches through constraining uncertainties on gauge data. Hydrology and H. S. S., 8(6), 1141-1152.

Wu W., 2004. Depth-averaged two-dimensional numerical modeling of unsteady flow and nonuniform sediment transport in open channels. Journal of Hydraulic Engineering, 130, 1013-1024.

Yu L.R., Righetto A., 1998. Tidal and transport modeling by using turbulence $\mathrm{k}-\mathrm{w}$ model. Journal of Environmental Engineering 124, 212-221.

\section{SUMMARY}

In land use planning along river paths it may be useful to consider the statistics of the flooding process of the river. The set of rules regulating land use planning in Italy results in the return period required being very long and, as a result, there are very high river discharge peaks which are taken into consideration and not much possibility of making experimental observations. Correct planning of land use should include some description of river flooding in these critical conditions. To do this a basin scale hydrological model and a robust numerical scheme of the 2D complete SWE have to be integrated. Knowing that experimental validation is very difficult we showed the reliability of the numerical schemes used to get consistent solutions. A watershed runoff forecast model was used to obtain the river hydrograph to apply as a boundary condition in the study of river flood inundation on the flat plain near the Olbia airport (Sardinia, Italy). A threshold of $1 \mathrm{~cm}$ was used as a condition to consider whether or not to include the cell in the computational field in the description of the wetting-drying process. And this seems to fit well in the model. The numerical model is conservative, ensuring preservation of water volumes with a precision of $10^{-4}$. The great surface water gradient in some sections is evident proof of the importance of the SWE inertial terms in wave front propagation. The flow peak loss during the alluvial plane flooding resulted in a reduction of about $10 \%$ of the discharge peak at the river mouth. This numerical method, which has been validated in previous similar applications, describes sufficiently well flooding in a complex area with river morphology limited by airport and road infrastructures.

Keywords: river flood inundation; shallow water equations, distributed hydrology model, finite difference method, wetting-drying algorithm. 